\title{
China cracks down on counterfeiters
}

In January 2009, two people died and nine were hospitalized in Xinjiang, China's far northwest province, after they took a counterfeit diabetes drug that contained six times the normal dose of the medicine's key ingredient, according to the state-run Xinhua news agency.

The news came as no surprise. In recent years, China has suffered a string of embarrassing scandals related to fake drugs that have taken the lives of hundreds of Chinese citizens and people overseas. Finally, however, after years of neglect, the government is showing new resolve to deal with the issue, with laws being tightened and government agencies stepping up their vigilance.

Last year, for example, the government launched a multiagency task force to crack down on illicit meds and those sold over the Internet. The group-composed of 13 ministries, including the State Food and Drug Administration (SFDA)-has carried out raids and made many arrests, according to two prominent American lawyers working in China. The task force has not officially made any reports.
"The government feels under more pressure because, at the end of the day, whether it's pharmaceuticals or food products or something a baby would use, [counterfeits] can have a direct consequence on public health," says Nicholas Blank, associate managing director of the Hong Kong division of Kroll, the world's largest risk consultancy firm.

According to Tony Chen, a patent attorney with Jones Day who represents several foreign drug companies in China, counterfeit drugs are rarely found in urban centers such as Beijing, Shanghai and Guangzhou, because hospitals there actively monitor their own drug procurement chains to protect their bottom line. "They could get hurt badly business-wise if people think a hospital pharmacy is selling bad medicines," he says.

Last year, the Supreme People's Court decided to classify drug counterfeiting as a criminal act if the fakes cause serious harm. As a result, many more of the small counterfeiting operations in the major cities have been shut down, according to a lawyer working with a drug company in Beijing. "The mom and pop [counterfeiters] are basically out of business," says the lawyer, who requested anonymity because the topic is highly sensitive in China. "Right now, the government is fairly aggressive in tackling the problem." Even so, some types of counterfeit drugs are still rife (see "In search of little blue pills").

Problems still persist in smaller cities and rural areas, where corruption is often more prevalent and regulation is not as tight. "Manufacturing is largely overseen by the provinces, and there's not that much coordination going on, so that's where the problems lie," says Roger Bate, an economist who studies counterfeit medicines at the American Enterprise Institute, a freemarket think tank in Washington, DC.

Nevertheless, because of the country's growing prosperity-China's economy grew $8.7 \%$ in 2009 despite the global recession-local health agencies now have the funds to carry out limited investigations and conduct research into wrongdoing in the industry. For example, local governments dispatch mobile labs to test the authenticity of medicines in distant, hard-toreach corners of the country (see page 361).

Paul Mooney, Beijing

\section{In search of little blue pills}

The sign on the front door describes the venue as an 'adult shop', a euphemism that adorns the plethora of small sex shops that dot China's capital. But step inside and you'll find a miniature drugstore carrying more than 60 medicines aimed at increasing male virility-each one likely to be a counterfeit.

The medicines-some of which cost upwards of 750 renminbi (\$110)—are locked behind a sliding glass door. I ask the store clerk if she sells Pfizer's Viagra, and the young woman, decked out in a nurse's white uniform and hat, reaches into her pocket and pulls out a set of jingling keys.

The pills are blue and appear to have the right markings. But they come in a bottle-and Pfizer doesn't sell Viagra in a bottle in China. The packaging clearly displays Pfizer's logo on the front, but the top flap says the contents were made by 'The US Institute of Biology'. Another telling sign is the blaring words on the front of the packaging, in all-capital letters: LONG-LASTING ERECTION.

Inside the bottles, the 'Viagra' comes in packets ranging from one to six pills each, but Pfizer only distributes the drug in two formats: one- and five-packs. At the sex shop, a pack of four sells for 180 renminbi-less than half the price of Pfizer's locally distributed pills.

When I question the authenticity of the pills, the clerk maintains that the medications are safe, and she pulls out a wide variety of other bottles and boxes, many with American-sounding names including USA Black Gold, American Prolong Time, USA Vermont, USA Super Viagra and American Ji Jie Hao (which has a photo of an American combat soldier).

A few blocks away in another adult shop, there are a wide variety of Chinese erection enhancers, but none with the word Pfizer on them. When I ask for Pfizer by name, the 'nurse' takes out a key and opens the closet door behind her. She rummages through a shoe box and turns around to display a wad of little blue tablets, each stuffed in tiny, individual Ziploc bags. The price sticker reveals that a single pill costs 300 renminbi, far above Pfizer's selling price for the drug in China. "These are imported from the United

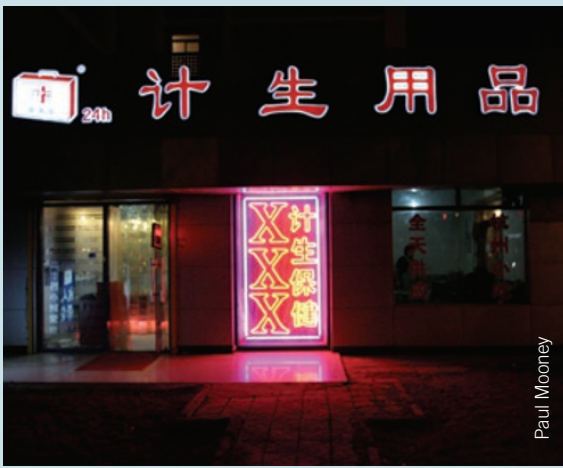

All nighter: A Beijing 'adult shop'.

States," she insists, adding that Pfizer's China products are made in local factories and so may be unreliable.

There are also a number of Chinese herbal remedies available, but even those may be fakes, and possibly dangerous, according to Fang Shimin, who runs the New Threads blog that exposes scientific corruption in China. "Many makers of TCM [traditional Chinese medicine] products add crushed Viagra to their medicines to make them appear to work," he says.

Paul Mooney, Beijing 